\title{
Prioridades del Nuevo Orden Mundial y Desplazamiento Forzado de Colombianos hacia Ecuador*
}

\author{
Consuelo Ahumada Beltrán* \\ Alvaro M oreno Durán**
}

\begin{abstract}
Resumo: 0 deslocamento transfronteiriço dos colombianos para os países andinos éo resultado da exacerbação dos fatores da violência e da deterioração das condições econômicas e sociais resultantes das prioridades da nova ordem mundial: a luta contra o narcotráfico, as políticas de liberalização econômica e comercial e "a cruzada mundial" contra o terrorismo. Oartigo analisa o deslocamento dos colombianospara a fronteira ColomboEquatoriana, especificamente até os Sucumbíos, por ser a província principal de recepcão dos deslocados do sul do país, e por considerar-se esta fronteira como uma das mais vulneráveis da Colômbia.
\end{abstract}

Palavras-Chave: Colômbia, Plano Colômbia, Iniciativa Regional Andina, Fronteira Colômbia/Equador, Deslocamento Populacional.

Resumen: El desplazamiento transfronterizo de colombianos hacia los países andinos es el resultado de la exacerbación de los factores de violencia y del deterioro de las condiciones económicas y sociales resultantes de las prioridades del Nuevo Orden Mundial: la lucha contra el narcotráfico, las políticas de liberalización económica y comercial, y la cruzada mundial contra el terrorismo. En este artículo se analiza el desplazamiento de colombianos hacia la frontera colombo-ecuatoriana, específicamente hacia Sucumbíos, por ser la provincia principal de recepción de los desplazados del sur del país, y por considerarse dicha frontera como una de las dos más vulnerables de Colombia.

Palabras-clave: Colombia, Plan Colombia, Iniciativa Regional Andina, Frontera Colombia/Ecuador, Desplazamiento poblacional.

*Este artículo es una síntesis de una investigación titulada: "El desplazamiento forzado de colombianos y su impacto sobrela región andina en el contexto del Nuevo Orden Mundial: el caso de Sucumbíos, Ecuador", que está en proceso de publicación

* Doctora en Ciencia Política de la New York University. Profesora titular de la Facultad de Ciencias Políticas y Relaciones InternacionaIes de la Universidad Javeriana. E-mail: cahumada@javeriana.edu.co.

${ }^{* * *}$ Candidato a Doctor en Políticas Sociales y Modos de Vida de la Universidad de París. Profesor de la FacuItad de Ciencias Sociales y Humanas de la Universidad Externado de Colombia. 
La reconfiguración del orden internacional que ha tenido lugar después del 11 de septiembre de 2001, y delasintervenciones delosEstados U nidosen Afganistán el rak en desarrollo dela cruzada mundial antiterrorista, hatraído un renovado interés dela política exterior estadounidenseen Colombiay en la región andina. Convertida en el escenario principal de la guerra contra el narcotráfico desdela década del ochenta, esta región ha venido afrontando crecientes presiones, en cumplimiento dedicha política. Si bien ésta se vienedesarrollando durantemás deuna década, hoy en díaseconcretaen el Plan Colombia y en laIniciativa Regional Andina, IRA, aprobada por el C ongreso delos EstadosU nidos como una estrategia antinarcóticosy antiterrorista para toda la región andina.

Estas estrategias se vienen aplicando en medio de una situación marcada por el incremento de la inestabilidad sociopolítica de los países del área, que se expresa en problemastalescomo lacrisiseconómica y social dela región, el fortalecimiento militar de suspaíses, la emergencia demovimientos sociales y políticos queexpresan el descontento de amplios sectores y la agudización de problemas tal es como el desplazamiento interno y externo dela población, como esel caso de Colombia.

En este contexto internacional, el desplazamiento transfronterizo de colombianos hacia los paísesandinos esel resultado dela exacerbación delosfactores deviolencia y del deterioro de las condiciones económicas y sociales resultantes de las prioridades del $\mathrm{N}$ uevo $\mathrm{O}$ rden $\mathrm{M}$ undial: la lucha contra el narcotráfico, las políticas deliberalización económica y comercial y la cruzada mundial contra el terrorismo.

En esteartículo seanalizael desplazamiento decolombianos haciala frontera colomboecuatoriana, específicamentehacia Sucumbíos, por ser la provincia principal derecepción delosdesplazados del sur del país, y por considerarsedichafrontera como una delas dosmásvulnerables deColombia.

El trabajo está estructurado en tres partes: la primera correspondeal marco teórico y estado del arte; en la segunda se examinan las principales estrategias del $\mathrm{N}$ uevo $\mathrm{O}$ rden M undial: el Plan Colombia y la Iniciativa Regional Andina; y la tercera analizael desplazamiento forzado en la frontera entre Colombia y Ecuador.

\section{Marco teórico y estado del arte}

El desarrollo del marco teórico y del estado del artedel presentetrabajo consta dedos partes. La primera recoge los principales enfoquesteóricos a partir delos cuales seexaminan las relaciones entre los EstadosU nidos y Colombia en losúltimos cinco años, en torno a tres temas que sintetizan las prioridades del $\mathrm{N}$ uevo $\mathrm{O}$ rden $\mathrm{M}$ undial: la política antinarcóticos, la cruzada antiterrorista y lasmedidas deliberalización económica. Estas estrategias se concretan en el Plan Colombia y en la Iniciativa Regional Andina. La segunda parte analiza al gunos de los planteamientos teóricos sobre el problema del 
desplazamiento forzado tran sfronterizo, desarrollados por académicos einstituciones internacional es y nacionales quese han ocupado del tema.

\section{A. Las relaciones internacionales y las prioridades del Nuevo Orden Mundial}

La analistamexicanaC CliaToro llamalaatención sobrecómo, a partir del decenio del noventa, prevalece en los ámbitos académicos la teoría de la interdependencia, o de la interdependencia compleja, paradar cuenta delos problemas delaregión. Señalaqueseha desarrollado un tipo deliteratura quebusca antetodo explorar las consecuencias políticas del incremento del comercio, lasfinanzas y lasinversiones entrelosEstados U nidosy los paíseslatinoamericanos. Acordecon el discurso económico y el enfoquepragmático predominantesen torno a las ventajasque ofrecelaglobalización paraestosúltimos, se privilegian los "nuevos espacios de acción" y las oportunidades que se presentan para los países de menor poder relativo, mientras que se destacan más las oportunidades que los riesgos. Proliferan entonceslosestudios decooperación internacional como mecanismos para corregir las "fallas del mercado" y reducir los costos detransacción (Toro, 1997). D eestaforma, todo el problema de las relaciones entre los Estados U nidos y los países de la región se reducea laformalización deacuerdos comercialesy a la creación deinstituciones bilaterales o multilaterales. Así seentienden, desdeestaperspectiva, proyectostan importantes como el Plan Colombiay la Iniciativa Regional Andina. Bajo esteenfoquepuedeentenderseque la estrategia principal de Plan seala erradicación decultivosilícitosmediantelafumigación, y que la lucha contra el terrorismo sea presentada por Washington y acogida por buena partedelosgobiernos dela región como un problema decooperación internacional en pos deladefensadeunosinteresescompartidos.

D esdeuna perspectiva teórica diferente, otros estudiosos del tema insisten en quela teoría del realismo sigueestando vigenteparael análisis dela política antinarcóticos delos EstadosU nidosen la región andina. Esta corrientepartedel predominio del Estado, de natural eza racional y egoísta, como actor central en el contexto delas relacionesinternacionales, dela definición desusinteresesen términos depoder y dela naturaleza eminentementeanárquica y conflictiva del sistemainternacional. D entro de ella seinscriben analistas como BruceBagley y Juan G. Tokatlián. ParaArleneT ickner, el realismo como "ideología" tiendea percibir el tráfico dedrogas como una amenaza "externa" a la seguridad nacional, másque como un problema "doméstico" (Tickner, 2001: 217).

Pero las explicacionesanterioreshan sido cuestionadas desdeteorías no clásicas delas relacionesinternacionales, talescomo el constructivismo. Q uienes defienden esteenfoque, desarrollado, entre otros, por Alexander Wendt, plantean que Colombia, mediante el desarrollo desu política exterior, hahecho parte activa delo quepodría denominarse "la 
formadominantedelacomunidad políticainternacional", quehasido socialmenteconstruida alrededor del problema de las drogas. Así, deacuerdo con Sandra Borda, existen actoresque "construyen, mediantesu interacción devalores, normasy símbolosqueguardan una relación constitutiva con la definición desusinteresesalargo plazo y desu propia identidad". Ello quiere decir que, en la lucha contralasdrogas, los intereses delosEstados U nidosy Colombiano están dados deantemano ni son impuestosmedianteel mero uso dela coerción, sino quecorresponden aun proceso histórico deconstrucción conjunta de unosmarcosdeentendimiento (Borda, 2002: 284). En estesentido sepronunciatambién ArleneT ickner, al señal ar que cuando se enfatiza exclusivamenteel peso de los Estados U nidosen la orientación delapolítica interna einternacional deC olombia, sesubestimael papel quehan desempeñado al gunosactorescolombianosen la "construcción deunaidea específica del paísfrenteal mundo", y seignoraquela relación bilateral con esepaís es "un proceso mutuo deinteracción social" (Tickner, 2002: 371).

En lo concerniente a la situación de Colombia y los demás países andinos como primera región productora decocaína en el mundo, y ala relación deestefenómeno con las políticaseconómicas vigentes, también sehan planteado diversas explicaciones. D arío Fajardo destaca que las regiones del sur del país, donde se cultivan prioritariamentela cocaína y la heroína, se caracterizan por ser zonas marginales, marcadas por un atraso secular en lasformas de explotación dela tierra y delas relaciones de producción que se generan; al mismo tiempo existen altosniveles de concentración de la tierra y una integración nacional quehasido difícil, debido a la pobre red vial existenteen el país, reflejo dela debilidad del Estado. A ello hay quesumarlela ausencia deun proyecto nacional articulador de la sociedad, el uso común de las armas para resolver los conflictos, la existenciadeuna configuración geográfica muy favorablealasactividadesilícitasaltamente rentables, y la pérdida creciente de la legitimidad en varios lugares del país. D eacuerdo con el autor: "Así como el empobrecimiento delascolonizacionescampesinas localizadas en laAmazonia y 0 rinoquiafacilitó el establecimiento dela coca, la crisis dela agricultura al interior dela frontera agrícolafueel escenario delairrupción dela amapola en lastierras fríasandinas" (Fajardo, 2002: 56-60).

Sobrelas explicaciones quese han dado de las relaciones entrelos EstadosU nidosy la región andina en torno al problema delas drogas, Francisco T houmi se refierea dos visiones quehan sido predominantes. Laprimera, defendida por un grupo significativo deanalistaslatinoamericanos, seinscribe dentro dela teoría dela dependenciay considera las drogas ilegales como expresión de las relaciones de dependencia entreel mundo desarrollado y el mundo subdesarrollado. D eacuerdo con esta visión, la producción de drogas ilícitas es el resultado de la naturaleza y las características del sistema mundial capitalista y refleja una profunda desigualdad en las relaciones internacionales. LosEsta- 
dosU nidosimponen sus políticas sobrelos países productores con el fin dealcanzar sus metas económicas y estas políticas constituyen un ataque directo a la soberanía de los países andinos (Thoumi, 2002: 59).

La segunda visión quesintetizaT houmi sedenomina moralista, es planteada por el sector más conservador en el establecimiento norteamericano y defiendeque "Iosvalores estadounidenses son universal es", por lo que los intereses de este país y el bienestar mundial coinciden. Por ello, la política antidrogas impuesta a los países andinos no debería entenderse como unaintervención imperial istatradicional, sino más bien como una estrategia que ben eficia a toda la humanidad (I bid.: 353).

Frente a los enfoques y planteamientos anteriormente expuestos, en el presente trabajo se señala queel análisis dela política antinarcóticos y dela cruzada antiterrorista, expresadas en el Plan Colombia y en la Iniciativa Regional Andina debe partir del contexto específico del $\mathrm{N}$ uevo $\mathrm{O}$ rden $\mathrm{M}$ undial, caracterizado por un incremento dela dominación einjerenciadelos EstadosU nidos sobrelos países dela región. A fines dela década de 1980, con su consolidación como único superpoder mundial, la región andina y particularmente Colombia pasaron a ser prioritarios en la nueva estrategia de la C asa Blanca y pasaron a convertirseen blanco principal dela misma.

A ese respecto, señalamos que el planteamiento del constructivismo en tomo a la participación activa de al gunos actores de los países andinos en las estrategias trazadas desdeWashington es acertado. Sin duda, la eliteneoliberal quese afianza en el poder del Estado en toda la región desempeña ese papel activo, en la medida en queseidentifica plenamentecon dichas estrategias. N o obstante, afirmar queéstas resultan de un proceso histórico de construcción conjunta, como lo hacela mencionada teoría, esminimizar el papel preponderantedesempeñado por losEstadosU nidosy su carácter marcadamente hegemónico en la región andina y en el mundo entero.

En efecto, debe destacarse la vigencia deuna perspectiva crítica deanálisisfrentea la injerencia norteamericana, como marco para entender las estrategias derivadas del N uevo O rden M undial. Refiriéndosea las explicacionesquesedieron en tomo ala crisis económica de la década del ochenta en América Latina, la norteamericana Barbara Stallings señala cómo los postulados previos en tomo a la influencia extranjera fueron abandonados con demasiada prontitud. "I rónicamente, en el momento en que las variablesinternacionales se volvieron más relevantes en los 80 , dichos planteamientos dejaron de considerarseel factor claveen las teorías del desarrollo", anota (Stallings, 1992: 61).

En cuanto a la agudización del conflicto en Colombia y a la forma como ello afecta los intereses delos Estados U nidos en la región andina y las relaciones entresus países, también se han pronunciado diversos analistas. Socorro Ramírez señala que la internacionalización de la problemática col ombiana seha incrementado por su desbor- 
damiento hacia las fronteras y "su compleja interacción con la situación de los países vecinos", los cuales seencuentran sumidos en una profunda crisis (Ramírez, 2001: 27). Ricardo Sánchez coincidecon esta apreciación, al señalar queel problema colombiano "se ubica en una crisis de fronteras, de relaciones con los países y Estados vecinos, en un contexto de desequilibrio de estas sociedades y susinstituciones" (Sánchez, 2001: 211). Por su parte, $M$ arthaA Adila destaca quelas situaciones relacionadas con la presencia delos grupos guerrillerosy losparamilitares, el incremento dela producción dedrogasilícitasy del tráfico dearmas, así como los efectos del Plan Colombia en las fronteras, guardan relación con la seguridad fronteriza, por lo quetanto losEstadosU nidos como los países vecinostemen quela situación colombiana desestabilicela región (Ardila, 2002: 317).

\section{B. El desplazamiento forzado: un marco de referencia}

Lapresentesección comienza con el recuento deal gunas definiciones sobreel desplazamiento y el refugio, formuladas por las organizaciones internacionales quese ocupan del tema. Enseguida sesintetizan algunos delos principales enfoques metodológicosy teóricos sobreel problema del desplazamiento forzado.

En cuanto a las definiciones sobreel tema, seseñala queen el "I nformeanalítico sobre desplazadosforzosos" (febrero de 1992) y en el "Estudio global del RepresentanteG eneral para asuntos dederechoshumanos relacionadosforzosos" (enero de 1993), laC omisión de D erechos $\mathrm{H}$ umanos de las $\mathrm{N}$ aciones U nidas define a los desplazados como "personaso grupos depersonasquesehan visto forzadasu obligadasa escapar o huir desu hogar o de su lugar de residencia habitual, en particular como resultado de un conflicto armado, situaciones deviolencia generalizada, violaciones de los derechos humanoso catástrofes natural es o provocados por el ser humano y en su propio país" (O acnudh, 2001: 19).

Por otra parte, el artículo $1^{\circ}$ (A) (2) de la Convención sobre el Estatuto de los Refugiadosy el Protocolo del Estatuto de los Refugiados definea un refugiado como cualquier persona quetenga

fundados temores de ser perseguida por motivos de raza, religión, nacionalidad, pertenencia a determinado grupo social u opiniones políticas, se encuentre fuera del país de su nacionalidad y no pueda o, a causa de dichos temores, no quiera acogerse alaprotección detal país; o quecareciendo denacionalidad y hallándose, a consecuencia detales acontecimientos, fuera del paísen donde antestuviera su residencia habitual, no pueda 0, a causa de dichos temores, no quiera regresar a él (I bid, 26).

D elos conceptos anteriores se deduceque, a diferencia del desplazado, el refugiado no sólo ha cruzado una frontera internacional mentereconocida, sino también haobtenido el estatus de refugiado por partedel gobierno del paísal cual llega. 
En cuanto alasinstituciones que se han ocupado del tema delos desplazados en el ámbito internacional seencuentran: Acnur, la G IM , la Cruz RojaInternacional, la GEA, el Consejo Internacional deAgencias Voluntariasy el Consejo M undial del glesias. En términosgenerales, dentro deuna visión muy limitada, estosorganismos relacionan el problema del desplazamiento forzado en Colombia con el reconocimiento del $D$ erecho Internacional H umanitario y con el respeto por los derechoshumanosen el país. LaC ruz Roja, por ejemplo, lo hace a partir de su principio fundamental deneutralidad, querige la misión del M ovimiento Internacional y dela M edia Luna Roja'.

El análisisinstitucional del problema delos desplazadosseinició a partir del documento Conpes N 0.2804 del 13 deseptiembrede1995, dondeseestablecieron loslineamientos principales para atender el fenómeno. En estedocumento sedefinieron como objetivos centralesla atención a la población ya desplazada y la neutralización delas dinámicas dela violencia, quegeneran fenómenos de desplazamiento. Estosobjetivos pretendían ser cumplidosa partir decuatro estrategias: prevención, atención inmediata, consolidación y estabilización socioeconómicay, finalmente, comunicación einvestigación.

En el proceso deaceptación del desplazamiento forzado como resultado dela violencia política en el país surgió la Ley 387 del 18 de julio de 1997, mediante la cual se reglamenta el Programa para la Atención Integral a la Población D esplazada. Esta ley busca adoptar medidas para la prevención del desplazamiento forzado, la atención, protección, consolidación y estabilización socioeconómica delos desplazadosinternos por la violencia en Colombia (Presidencia de la R epública, 1998). N o obstante, las políticas adoptadas por losúltimosgobiernos, relativasal nuevo modelo de desarrollo y a estrategias como el Plan C olombia, van en contravía de lasmedidas planteadas en dicha ley, como veremosen el estudio sobreel Putumayo.

El desplazamiento forzado en Colombia se ha estudiado desde diversos enfoques. Existeuno basado en las "historias devida" como fuenteprincipal para la reconstrucción histórica y periodística del fenómeno. Este enfoque, que plantea una postura crítica frentea las condicionespolíticas, económicasy socialesquepropician el desplazamiento en Colombia, es desarrollado, entre otros, por los trabajos deAlfredo M olano (1985, 1990,2001) y de G ermán C astro C aycedo (2003).

En un plano más estrictamenteacadémico, el tema ha sido abordado desdedistintas perspectivas. En primer lugar, están quienes trabajan el marco del conflicto armado

${ }^{1}$ Estatutosdela Sociedad Nacional dela Cruz Roja Colombiana aprobadosporla X Convención Nacional ExtraordinariaEstatutaria, febrero de 1996. Convenio de Ginebra del 12 de agosto de 1949. Richard Perruchoud, Derechos y deberes intemacionales delas sociedades nacionales y dela Media Luna Roja, Instituto Henry Dunant, Ginebra, 1992. 
interno, como los investigadores del IEPRI, JaimeZuluaga $\mathrm{N}$ ieto (2002) y M auricio Romero (2002). Esteenfoqueanalizalosdistintosprocesos políticos, incluido el desplazamiento forzado, a partir dela intensificación y degradación dela guerra y dela relación entre sus diversos actores. ParaZ Zuluaga, la guerra quevive Colombia es el resultado dela ausencia de procesos reformistas que posibilitaran el acceso delossectores popularesalos beneficios del crecimiento económico y de la ciudadanía. A ello se suman los elevados niveles deinequidad y exclusión; la existencia deun Estado incapaz de regular losconflictos sociales, y de un sistema político queha bloqueado el desarrollo de una democracia moderna. En síntesis, señal a que la guerra en Colombia es síntoma de una carencia de institucionalidad democrática, situación quese considera de vital importancia para quese produzcael fenómeno del desplazamiento forzado. Para Romero, por su parte, esfundamental examinar lasinteraccionesentreel campo político legal ylasorganizacionesilegales, y lasestrategias delosactores regional es para plantear coalicionescon los gobiernoslocales.

U na segunda tendencia desde la cual se analiza el desplazamiento forzado es la relacionada con la tenencia y uso de la tierra y con las disputas territoriales. Como representantes de dichosestudios están lostrabajos deAbsalón M achado (1998) y D arío Fajardo (2001). El primero deellosseñalaqueel avance dela gran propiedad, el deterioro dela mediana y la continua fragmentación dela pequeña propiedad han sido fenómenosacompañados deviolencia, desplazamientos ruralesy masacres continuas. La característica de losnoventas es la conformación de una gran propiedad con ejércitos propios que defienden los latifundios como en las épocas feudales y los cultivosilícitoso zonas estratégico-militares. "Setrata, entonces, de unainvolución en la estructura agraria, que refleja la pérdida de dominio territorial por parte de las autoridades y la acentuación de un Estado patrimonial en el queintereses privadospriman sobrelos de la colectividad", señala (1998: 56). D eacuerdo con D arío Fajardo, el conflicto colombiano, y por lo tanto el desplazamiento forzado, tiene sus raíces en viejos problemas no resueltos, como el de lasrelaciones políticas, económicasy sociales, derivadas del grado de concentración dela propiedad delatierra.

0 tro enfoquees el queanalizalos desplazamientosurbanos, y entre susrepresentantesse encuentran G loria N aranjo y D eicy H urtado, dela U niversidad deAntioquia. En sus palabras, el desplazamiento urbano produce un impacto sobrela subjetividad y la transformación delas coordenadas espacio-temporales delos desplazados, queson claves para entender cómo se da "el progresivo cambio del significado del espacio y del tiempo y sus profundas consecuencias en el mundo delosvalores, actitudes, lasmotivaciones, los estiloscognitivos", situaciones queinducen a "nuevasestrategias, nuevosretos, tensiones y negociacionesen laciudad". Esteenfoquepretendesuperar las visionesestigmatizadoras sobrelos migrantesy desplazados por la violencia, y proponereconocer cómo los aportes 
culturalesy sociopolíticos delosnuevos habitantesquellegan contribuyen ala configuración delasciudades ( $\mathrm{N}$ aranjo y $\mathrm{H}$ urtado, 2002: I).

Los procesos organizativos y de resistencia dela población desplazada, sus al cances, limitaciones y retos, son estudiados por Juan M anuel Bustillo (2001). Según este autor, la resistencia dela población desplazada ha tenido antecedentes en las movilizaciones y protestas campesinascívicas eindígenas. $\mathrm{N}$ ormalmenteel punto quesiempre reclaman es la presencia estatal a través de obras deinfraestructura básica, salud y educación. D ebido a las fumigaciones, sehan dado paros importantes, como el realizado entre finales de 1994 y comienzos de 1995, y el de 1996, que congregó aproximadamente a 57.000 campesinos, en su mayoría cultivadores decoca, quesedesplazaron a los cascosurbanos deM ocoa, Puerto Asís, G rito, San M iguel y laH ormiga. En aquella ocasión demandaban el cumplimiento de los acuerdos firmados en el año 1995, la suspensión de las fumigacionesy la obtención del reconocimiento social dela problemática delospequeñoscultivadores dehoja de coca. Q uienes trabajan en estetema, recopilan los antecedentes históricos y hacen los análisis de las causas y consecuencias de los hechos que Ilevan a la resistencia, en laque están involucrados los desplazados.

Por último, estáel tema dela llamada cooperación internacional y las experiencias de acompañamiento a la población desplazada, estudiado por Richard N ordgren (2000). D esdeuna perspectiva crítica, señal a queel papel delas organizacionesinternacionales está relacionado con las políticas de los Estados U nidos, enlazadas a su vez con los intereses económicos de las multinacionales. Las situaciones de conflicto territorial, la agudización delascrisis deC ol ombia y sus países vecinos y el desplazamiento transfronterizo son analizadosy eval uados frenteal desarrollo delos grandes proyectos políticosy económicosquepromueven inversionesen zonasestratégicas, dentro deellas laszonas de conflicto. Entre estos proyectos están el Plan Colombia, el Plan Puebla Panamá, la Iniciativa Regional Andina y el Acuerdo del LibreC omercio delasAméricas, ALCA. Los estudios del desplazamiento forzado serel acionan con losintereses antes mencionadosy tienen como elementos comunes la evaluación de los potenciales impactos de estos planes globales en todos los aspectos de la vida económica, política, social, cultural y ambiental (Gruner, 2002).

Por último, el tema delasfronterasy el desplazamiento ha sido estudiado por entidadescomo CO D H ES (2001), el International C risis G roup (2003) y el O bservatorio Andino de laU niversidad J averiana (2003), Estalínea temática estudia el desplazamiento en las zonas de fronteras, en conexión con las políticas internacionales.

El enfoquedel desplazamiento forzado queseplantea en el presentetrabajo partedel análisis dedicho fenómeno en el contexto delos cambiosen las relacionesinternacionales dela región andina, delas políticas derivadas del $\mathrm{N}$ uevo $\mathrm{O}$ rden $\mathrm{M}$ undial, y delaforma 
como en losúltimostiemposdichoscambiosy políticas han afectado los procesospolíticos, económicos, sociales y culturales de los países de la región y sus fronteras. Este enfoqueintegral pretendesuperar las limitaciones delos enfoques anteriormente descritos, que, en términos generales, no abordan el fenómeno del desplazamiento forzado en dicho marco internacional.

\section{La estrategia del Nuevo Orden Mundial: del Plan Colombia a la Iniciativa Regional Andina}

Tanto por su procedencia como por susobjetivos, el Plan Colombia ha despertado unafuertecontroversianacional einternacional a partir del momento en queseanunció, a mediados de 1999, y se presentó al Congreso de losEstados U nidos para su aprobación en octubre del mismo año. D os posicionesopuestas se han expresado frentea esta estrategia norteamericana. La primera, por parte de sus defensores, los gobiernos de los dos países, que insisten en presentarlo como un "Plan para la paz, la prosperidad y el fortalecimiento del Estado", y como una panacea para todos los males que afligen a la nación. La segunda, encabezada por diversas organizaciones políticas y sociales, entre ellas los sindicatos y numerosas ON G que se mueven en el ámbito internacional y nacional, quehan insistido en queel Plan Colombiano haría másqueincentivar la guerra y la crisis social debido a su carácter marcadamentemilitarista².

Sin embargo, poca atención seha prestado a losaspectos más preocupantes del Plan. $\mathrm{H}$ ay que partir del hecho de que su versión definitiva fue elaborada a partir de las apreciaciones de una comisión del gobierno norteamericano que estuvo dos meses en Colombia, y fuediscutido y aprobado en el Congreso delosEstados U nidosantes deque seconocierasiquiera en nuestro país. Anteel malestar expresado por varios sectores políticos por tan anómalasituación, en especial al gunoscongresistas del partido liberal, el gobierno dePastrana descalificó cualquier crítica con el argumento dequequien osara cuestionar el Plan eraun enemigo dela paz y dela inversión social (Acosta, 2001: 70-73).

\section{A. EI Plan Colombia y la fumigación de cultivos ilícitos}

U no de los aspectos más cuestionados del Plan Colombia ha sido su estrategia antinarcóticos, centrada en la fumigación aérea decultivosilícitos. Losgraves efectosque

\footnotetext{
${ }^{2}$ Para conocer visiones en mayor o menor medida críticas sobre los distintos aspectos del Plan Colombia y de la Iniciativa Regional Andina, ver los artículos de los libros: ÁLVAREZ, J. E. (compilador), EI Plan Colombia: Ensayos críticos, Universidad Nacional de Colombia, 2001; IEPRI, El Plan Colombia v la nternacionalización del conflicto, Planeta, 2001; y ÁLVAREZ, J. E. (compilador), El Plan Colombia y la intensificación de la guerra, Universidad Nacional de Colombia, 2002.
} 
ello causa sobre las condiciones de vida y de salud de la población, la destrucción del medio ambiente, de los cultivos de supervivencia y de las fuentes de agua, han sido objeto dedenuncia permanentea nivel internacional. Tampoco podría dejar de mencionarsesu impacto nefasto sobre las condiciones sociales dela región, quese expresa en el incremento del desplazamiento forzado defamiliasenteras hacialos países vecinos, pero especialmenteal Ecuador. Según cálculos del mismo documento aprobado del Plan Colombia, cerca de 400 mil personas tendrían que salir forzosamente, por lo que se asignó un recurso deinversión social con el fin deproveer atención en campamentos para lasfamilias afectadas.

D eacuerdo con un informe del Comité de losEstadosU nidospara los Refugiados (USCR), una O N G estadounidense, en Colombia hay 2.45 millones de desplazados, de loscuales el 47 por ciento son mujeresy niños, lo que convierteal país en el segundo del mundo con la población másalta en desplazadosinternos, solamente después deSudán. El informe responsabiliza al Plan Colombia por el desplazamiento de más de 36 mil personas duranteel 2001 y afirma que 42 pueblosfueron completamenteabandonados durante esteperiodo ${ }^{3}$.

Sin duda, la fumigación aérea es una de las estrategiasvitales del Plan Colombia. En abril del 2002, altos funcionarios del $D$ epartamento de Estado anunciaron quesu país cancelaría los programas de sustitución de cultivosquevenía financiando en Putumayo y C aquetá. Esteprograma de desarrollo alternativo aparecía como uno delosejes del Plan Colombia, pero dosreportes oficialesdelosEstadosU nidos, uno delaGAO (Controladoría General del C ongreso) y otro del D epartamento de Estado, habían advertido queel programa no estaba funcionando (ARI, 2003: 10). Estas afirmaciones en torno al fracaso dela erradicación manual permiten entender el énfasisfundamental quele están proporcionando a la fumigación aérea. En este sentido, el Subsecretario de Asuntos Antinarcóticos del $\mathrm{D}$ epartamento deEstado norteamericano, Rand Beers, había afirmado tiempo atrás en forma tajante: "Intensificaremos las fumigaciones", y agregó: "Sí, vamos a fumigar todo el país para quela genteentienda que está corriendo un riesgo" 4 .

\section{B. El giro hacia la cruzada antiterrorista}

En enero de 2000, la llegadaal poder de la C asa Blanca del grupo de "los halcones", representado por el sector más conservador del Partido Republicano, trajo un fortaleci-

\footnotetext{
${ }^{3}$ Sudán y Colombia: 1-2 en desplazados", E! Tiempo, 7 de junio de 2002, p.1-20.

4 "Intensificaremos las fumigaciones", El Tiempo, septiembre 1 de 2001, p.1-3.
} 
miento dela política represiva de losEstados U nidosfrenteal narcotráfico. Este sector estárepresentado por el mismo presidenteBush y losaltosfuncionarios desu gobierno.

Sin duda, losatentados del 11 de septiembrey la cruzadaglobal contra el terrorismo, convertida en prioridad dela política exterior delos Estados U nidos, reafirmaron esa tendencia hacia una mayor represión. En consonancia con el giro quese presenta después de este episodio, los pronunciamientos de losfuncionarios deW ashington sobre Colombia empezaron a reflejar la nueva situación, y lasFARC pasaron deser una "organización narcotraficante" para convertirseen una guerrilla "terrorista" queamenaza la seguridad hemisférica ${ }^{5}$.

En medio dela feroz reacción desatada por los atentados deseptiembre, el gobierno delosEstados U nidostomó la decisión de reforzar lalucha contra el terrorismo en toda la región. "M i oficina está trabajando con las diferentes agencias del gobierno para diseñar una estrategia antiterrorista para Colombiay otros países andinos", afirmó por ese entonces el mismo FrancisTaylor. Esta estrategia está diseñada para complementar el Plan Colombiay la Iniciativa Regional Andina 6 . M eses después, los Estados U nidosy los países andinos se comprometieron a desarrollar una estrategia común delucha contra los gruposterroristas querecurren al narcotráfico. Tal fuela decisión dela reunión sostenida entrelosmandatariosde losEstadosU nidos, Colombia, Perú, Boliviay el vicepresidente deEcuador, el 24 de marzo del 2002 en Lima.

El apoyo a laBrigadaXVIII para defender el oleoducto Cafio Limón-Covefias marcó un giro significativo dela política exterior hacia Colombia, al igual queel cambio que aprobó el Congreso de ese país frente al uso de la ayuda militar. En efecto, decidió destinar 98 millones de dólaresa esta brigada, con el objeto de dotar y capacitar a cerca de 4 mil soldados, así como para la adquisición dedocehelicópteros, con el fin de darle movilidad a la brigada.

Por último, en latrigésima segundaversión dela Asamblea G eneral de la O rganización deEstados Americanos, reunida en Barbados a comienzos de junio del 2002, se aprobó por absoluta mayoría una nueva Convención Interamericana contra el Terrorismo. Lospaísesmiembros dela O EA secomprometieron aincrementar su cooperación y a hacer más estrictossus controles fronterizos, así como a confiscar los fondos y los bienes de los grupos identificados como terroristas. U n punto cardinal de esta convención, indudablementeel quemás preocupa desdeel punto devista delos derechos elementa-

${ }^{5}$ Arlene E. Tickner, “Bush, Hollywood y las F ARC”, El Tiempo, febrero 3 de 2002, p. 124 ${ }^{6}$ bid. 
les de las personas, es que por primera vez se excluye los motivos políticos como causa para negar la extradición de alguien a quien se le acuse de un ataque terrorista, y los Estadosse comprometen a negar asilo o estatus derefugiado a cual quier persona contra la cual existan "razones fundadas" para considerar queha participado en terrorismo?.

\section{La Iniciativa Regional Andina: componentes y significado}

La Iniciativa Regional Andina, presentada al Congreso por el presidenteBush en abril del 2001 y aprobada poco tiempo después, prevéextender la estrategia antinarcóticos y antiterrorista del Plan Colombiaa los países limítrofes con el nuestro. Parael desarrollo de este programa, en el 2002 se asignaron 882 millones de dólares a siete países de la región: Colombia, Perú, Bolivia, Ecuador, Venezuela, Brasil y Panamá.

D eacuerdo con documentos oficial es del gobierno de los Estados U nidos, la región andina es importante para ese paíspor lassiguientes razones: primera, en ella se encuentran lostres principales productoresdedroga, queresponden por el ciento por ciento de la cocaína y el 60 por ciento de la heroína que entran al mercado de Estados U nidos; segunda, en la región hay dosimportantes productores de petróleo, Venezuela y Ecuador, que leproporcionan a los Estados U nidosuna cantidad significativa de crudo y son miembros de la O PEP; tercera, este país es el principal socio comercial de todas las naciones andinasy, cuarta, allí seencuentran al gunos delos países demayor población de Latinoamérica, incluidosBrasil y Colombia(ARI, 2003: 9).

En desarrollo dela I niciativa Regional Andina, el 4 defebrero del 2002 el presidente Bush presentó su proyecto depresupuesto ordinario para las 0 peraciones en el Extranjero del año fiscal 2003 ( 1 de octubre del 2002 al 30 de septiembre del 2003), en el cual incluyó 731 millones de dólares para el combate al narcotráfico en la región andina, canalizadosmediantelaI niciativaAntinarcóticosAndina (Andean Counterdrog I nitiative $\mathrm{ACI}$ ). Lasautoridades norteamericanas esperan queC olombia, quesiguesiendo el mayor receptor, erradique en el 2003, 200 mil hectáreas de coca (el doble del 2002) y 10 mil deamapola $a^{8}$. A parte de los recursos para combatir el narcotráfico, la I niciativa incluye ayuda para el fortalecimiento dela democracia y el desarrollo en la región.

$D$ entro delosargumentos queel gobierno de los EstadosU nidosha esgrimido para impulsar la IRA se encuentra la necesidad de abordar la preocupación de los países vecinosaC olombia por la expansión delos problemas relacionados con el narcotráfico y

7 "OEA, firme contra el terrorismo", El Tiempo, junio 4 de 2002, p.1-16.

8 "Llegó 'la pesada' de E.U.", El Tiempo, febrero 5 de 2002, p.1-6. 
gobierno estadounidense expresa su preocupación frenteal hecho dequeen la región andina la democracia sevea cada vez más amenazada por una multiplicidad de factores asociados, entreotros, a la debilidad de las instituciones democráticas, la corrupción y la crisis económica. En la óptica estadounidense, ha habido un incremento de movimientos políticoscatalogadoscomo no democráticos, queexpresan resistencia antelas actuales condiciones sociales, económicasy políticasqueseviven en la región ${ }^{14}$.

LaIniciativa Regional Andina examina también, de manera particular, la situación dela insurgencia y del proceso depaz en Colombia. Al respecto, aunqueel gobierno de losEstados U nidos recal ca la necesidad de resolver el conflicto colombiano por la vía pacífica, considera que un proceso de paz negociado en estos términos requeriría de mucho tiempo y effuerzos, por lo que la solución inmediata debe consistir en reducir el financiamiento de la insurgencia a través del tráfico de drogasilícitas, medianteel fortalecimiento de las fuerzas armadas del Estado. Este objetivo se complementa con el propósito de contener la violencia que desde Colombia puede trasladarse a los países vecinos, preparando a las regiones fronterizas para a un posibleflujo derefugiados por medio deprogramas deayuda para el desarrollo alternativo. N o obstante, másallá de lo quese plantea en este documento oficial, en la práctica, la estrategia principal y determinantefrenteal problema delos cultivosilícitosno es otra quela deintensificar lafumigación aérea, como ya seseñaló.

En lo querespectaal desarrollo económico y el comercio, el gobierno estadounidense recalca la necesidad quetienen losEstados de la región de estabilizar sus economías por medio delas denominadas reformas estructurales que han venido poniendo en práctica en estos países a partir de la década de los noventa. Con dichas políticas se pretende estabilizar ala región en materia económica y, por ende, fortalecer la democracia ${ }^{15}$.

La renovación de la AT PA (Acuerdo de Preferencias A rancelarias para la Región Andina, ahora conocida como AT PD EA), también hacepartedelos puntosfundamentales del tema de desarrollo y comercio en laIniciativa Regional Andina. Esteacuerdo fue introducido por el PresidenteBush padre como parte de la estrategia antidrogas desu país y cubrea lospaíses andinos, con excepción deVenezuela. Sin embargo, para acceder efectivamentea los limitados beneficios de dicho acuerdo, los países debieron demostrarle al gobierno de los Estados U nidos que cumplían con veintiún requisitos, que se refieren atemas como la no expropiación, el respeto a la propiedad intelectual, la elimi-

${ }^{14}$ Colombia Project. The Center for International Policy's, Hoja informativa Del Departamento de Estado sobre la política de Estados Unidos con respecto a la región andina, mayo 17 de 2001. p. 2 de 15.

${ }^{15} \mathrm{Bbid}$, p. 7 de 15. 
nación delos subsidios a las exportaciones, el compromiso con el ALCA, además del respeto a losfallos delos tribunales dearbitraje. En tal sentido se pronunció el secretario adjunto deC omercio dela pasada administración norteamericana, W illiam Lasb, durantesu visita aC olombia a fines de abril del 2002: "EI ATPA fuecreado para compensar a lospaíses en su lucha contra las drogas, pero los beneficiosno pueden ser gratuitos", señaló con claridad ${ }^{16}$.

D ela misma manera, losEstados U nidoshan querido integrar el Acuerdo de Libre Comercio de las Américas, ALCA, a laIRA. Por ello, la Iniciativa insisteen la necesidad de la liberalización comercial que según el gobierno estadounidense se ha desenvuel to de manera desigual en la región. Se evidencia la preocupación del gobierno porque la mayoría desus países mantienen todavía barreras al comercio y la inversión, queretardan el crecimiento económico.

\section{La frontera entre Colombia y Ecuador: una situación crítica}

EI sur del país y el territorio que comprende la frontera colombo-ecuatoriana se constituyen en la zona más importante de aplicación de las estrategias antinarcóticos dirigidas por los Estados U nidos, por cuanto es uno de los territorios aptos para la siembra decultivosilícitos.

En este contexto, Ia Iniciativa Regional Andina pretende crear un muro militar de contención frentealos actoresarmadosy los cultivosilegales. Sin embargo, lasacciones militares hasta ahora adelantadas parecen haber desembocado, no precisamenteen una reducción del problema de las drogas, sino en la profundización de la crisis social y humanitaria que se expresaa través de los múltiples desplazamientostransfronterizos, y la situación deconflicto y tensión militar que sevive en la frontera.

L as estrategias militares y social es llevadas a cabo hasta ahora en la región y más particularmenteen Colombia, están incrementando el desalojo y la expropiación violenta de campesinos, comunidades indígenas y negras, así como los atropellos contra el medio ambientey $\mathrm{el} D$ erecho Internacional $\mathrm{H}$ umanitario.

\section{1) Las cifras del desplazamiento forzado}

Las alteraciones del mapa sociodemográfico de Colombia como consecuencia delos desplazamientos por la violencia, cuyo resultado es la fragmentación, polarización y

16 “E.U. lanza ultimátum”, El Tiempo, abril 30 de 2002, p.1-12; “Los pasos para el ATPA”, El Tiempo, mayo 27 de 2002, p.2-9. 
desintegración dela sociedad, tienen como muestra representativa el caso delas fronteras con Colombia. D e acuerdo con Jorge R ojas, presidente de Codhes, "en las zonas de frontera se mantiene la ten dencia de migraciones forzadas de carácter temporal, que responden a las dinámicas del conflicto armado y queafectan territorios de países vecinos, cuyos gobiernos insisten en medidas restrictivas que agravan la crisishumanitaria" (Rojas, 2003: 44).

En un contexto de violencia generalizada, cuyos rasgos sobresal ientes han sido un incremento delas disputasterritoriales entreparamilitaresy guerrilleros, laamenaza contra las autoridades locales, el acentuamiento de las políticas represivas del Estado y de las fumigaciones aéreas, el problema del desplazamiento forzado de colombianoshacia los países vecinos ha aumentado demanera notoria. Siguiendo las estadísticas recogidas por Codhes, esteproblemasevolvió especialmenteagudo en los departamentosfronterizoscon Ecuador, Venezuela y Panamá, países a los cuales cruzaron, sólo entre los años 2000 y 2001, alrededor de 37 mil compatriotas. Según documentos oficiales, en las naciones mencionadas cerca de 6 mil ciudadanos presentaron solicitud de refugio, de las cuales aproximadamente 1.800 fueron aceptadas, en su mayoría en Ecuador. Seestima quesólo diez de cada cien colombianos que cruzan la frontera en busca de refugio y protección presentan solicitud oficial a losgobiernos delos países vecinos, y sólo a cinco de esos diezse les otorga el estatus derefugiado, en tanto quelos demássiguen indocumentados ${ }^{17}$.

En lo querespecta a Ecuador, en losúltimoscuatro años los efectos dela crisisinterna colombianahan venido afectando de maneranegativala frontera, aumentando losíndices dedelincuencia común y criminalidad en la región. Esto sedebea las acciones delos gruposcolombianosal margen delaley, guerrillay paramilitares, quebuscan esconderse delas autoridadesen la selva ecuatoriana. Adicionalmente, se haincrementado el número de personas desplazadas por la violencia hacia localidades en la frontera como Lago Agrio (hoy N ueva Loja) y C archi, deteriorando losindicadores socioeconómicos dela zona. Este desplazamiento ha aumentado considerablemente desdelaimplementación del Plan Colombia en el Putumayo, a partir de diciembre del 2000. La I glesiaC atólica, ACN U R y otras entidades, sostienen quela mayor cantidad dedesplazados que cruzan la frontera desdeC olombia procedede los departamentos deN arino y Putumayo. Este último concentra la mitad delas más de 140.000 hectáreas decultivos decoca y amapola existentesen el país. Loscampesinoscolombianos sehan refugiado mayoritariamenteen Santo D omingo delosC olorados, Carchi, Esmeraldasy Sucumbíos.

${ }^{17}$ Ibid; La Hora, Quito, mayo 15 de 2003. 
Señalemosquelas poblaciones colombianasy ecuatorianas dela frontera han tenido una relación de vieja data, pues las migraciones deC olombia a Ecuador y viceversa son tan antiguas como el comercio entre los dos países. En la provincia de Sucumbíos ha habido desplazamientos decolombianos desdeel decenio delos50, por lo que se puede creer que muchos de los actuales desplazados buscan refugio entre sus familiares. La primera oleada importante demigración de colombianos se presentó en los anos 70 , a raíz de las actividades de producción y exportación de petróleo en Ecuador. Esto hizo quecambiarala dinámica poblacional en Sucumbíos debido a los nuevosasentamientos demigrantes colombianos. U na segunda ol eada demigrantes provenientes del sur del paísseinició en 1998. Estegrupo está conformado en su mayoría por población campesina quesaledebido al a difícil situación económica, el abandono del Estado, la presión delosactores en conflicto y más recientemente por lasfumigaciones.

El incremento del número de desplazados colombianos en el Ecuador durantelos últimos tres anos ha sido notorio. D e acuerdo con José Euceda, representante de la AC N U R en el país, en el censo del 2001 aparecieron registrados 51.000 colombianos $^{18}$. Entreel 2000 y mediados del 2003, Ecuador ha recibido 16.100 solicitudes de refugio decolombianos. $D$ atos de esta entidad señalan quelas solicitudes se incrementaron en un 50 por ciento entre agosto y septiembrede 2002, provenientes de los departamentos colombianos antes mencionados. El incremento responde a la intensificación de las fumigaciones de cultivos en el sur de Colombia, al recrudecimiento de los combates entreel Ejército y a la acción de losgrupos armados. D eacuerdo con distintas fuentes, entreellas al gunos líderes campesinos detales departamentos, muchos de los labriegos huyen hacia Ecuador debido a las aspersiones y a los daños que han provocado en la salud dela población, losanimales y loscultivoslícitos ${ }^{19}$.

D e la misma manera, para el ministerio de Relaciones Exteriores de Ecuador el incremento del desplazamiento de colombianos es preocupante. M ientras quedurante la década del noventa hubo un promedio de 60 solicitudes de refugio por año, el problema se agudizó en e12000, cuando de golpe se recibieron 413 solicitudes de refugio, 323 de las cual es correspondían a colombianos (78.2 por ciento). En el 2002 hubo 6.270 solicitudes, delas cuales 6.244 (99.6 por ciento) correspondieron a colombianos. La distribución de estaúltima cifrafue: 749 solicitudes en el primer trimestre, 1.462 en el segundo trimestre, 1.563 solicitudes en el tercer trimestre y 2.496 en el cuarto. En el primer trimestre del 2003 serecibieron 5.142 solicitudes, un promedio

\footnotetext{
${ }^{18}$ Entrevista personal con José Euceda, Quito, abril 4 de 2003

19 "Record depedidos de refugio en octubre", Diario Norte, octubre 14 de 2002, p.31 ; La Hora, mayo 15 de 2003.
} 
mensual de 1.285, 42 casos por día. Entreenero de 2002 y enero de 2003 se presentó un incremento del 1.100 por ciento, y entreenero del 2000, cuando se registraron 13 solicitudesy enero de 2003, el incremento fuede 12.630 por ciento ${ }^{20}$. Lo mássignificativo es que estas personas desplazadas por la violencia no son necesariamentecampesinos provenientes dezonas rurales, sino personas que están huyendo dela guerra urbana de los grupos armadoscolombianos ${ }^{21}$. Adicionalmente, por información recientedelaC ancillería se sabeque los refugiadosno están en albergues dela línea defronterasino quese establecen en casi todas las provincias del país. Cerca del 40 por ciento delas personas quehan solicitado refugio está en Q uito, mientras queel resto se encuentra en Guayaquil, I barra, Ambato y otras ciudades.

Esta situación, sumada ala evidente incapacidad institucional delosEstadospara implementar la Ley 387 parala prevención del desplazamiento y protección dela población desplazada por el conflicto, y a la falta dedirectrices claras para atender a los desplazados por la erradicación de cultivos ilícitos, propicia el desbordamiento de la crisis humanitaria quese viveen la frontera norte.

Sin embargo, lo cierto es que la cifra de desplazados por el conflicto colombiano puedeser mucho mayor delo que muestran lasestadísticas, puessetrata de personas que no sólo no seidentifican como tales, sino que ponen en riesgo su vida y la de su familia si solicitan refugio ${ }^{22}$. D e acuerdo con el funcionario de alto nivel del ministerio de Relaciones Exteriores deEcuador antes mencionado, del considerablenúmero de desplazados procedentes de Colombia, sólo al rededor de un 5 por ciento solicita el estatus derefugiado $0^{23}$.

O tros funcionarios estatales en Ecuador han considerado también como crítica la situación en lafronteranorte. Francisco Javier Bonilla, Coordinador delasO rganizaciones de $\mathrm{D}$ erechos $\mathrm{H}$ umanos de la $\mathrm{D}$ efensoría del Pueblo deEcuador, considera que de al guna manera la guerra o la violencia de Colombia se va a trasladar a su país. Esto se confirma con laocurrencia deactos deviolencia delincuencial en la mayoría delos cuales están involucrados lamentablementeciudadanoscolombianos. Parael funcionario, esto

\footnotetext{
${ }^{20}$ Entrevista personal a Fabián Valdivieso Eguiguren, Director General de Derechos Humanos, Asuntos Socialesy Ambientales, Ministerio de Relaciones Exteriores, Quito, abril 3 de 2003; El Comercio, Quito, junio 18 de 2003. ${ }^{21}$ Ibid; El Universo, Guayaquil, Ecuador, 27 de mayo de 2003.

22 El Comercio, junio 18 de 2003.

${ }^{23}$ Entrevista personal a Fabián Valdivieso Eguiguren, Director General de Derechos Humanos, Asuntos Socialesy Ambientales, Ministerio de Relaciones Exteriores, Quito, abril 3 de 2003. "EI colombiano que llega a Ecuador se camufla muy fácilmente, debido a las similitudes étnicas, culturalesyreligiosas....Definitivamente, para Ecuador este problema sí representa un conflicto y una situación anómala", señaló.
} 
ha generado en la ciudadanía una situación de precaución. máxima, demiedo permanentey, aunqueno se pueda decir xenofobia, sí hay una actitud detemor. Estasituación estárelacionada con el problemadel Plan Colombia ${ }^{24}$. Al respecto, afirma que "muchas personasno pasan por el puesto defrontera, sino por otros lados (...) lafrontera es extensa y por cualquier lado pueden pasar y lo hacen, entonces el hecho dequeellos entren sin documentosles poneen evidencia y en sospecha rápidamente". A esto se suma queen Ecuador seconocequeel presidenteÁlvaro U ribeestá dispuesto a combatir a la guerrilla y al narcotráfico, con las consecuenciasqueesto supone, incluido el traslado dela violencia a estepaís, "ustedes ya constataron cómo seviveen Lago Agrio, para nosotrosel tema deLago Agrio esun tema quenos asusta mucho"25.

LaC omisión de BuenaVecindad, conformada por los dosgobiernos para afrontar el tema del desplazamiento, determinó la existencia detreszonasvulnerables en la frontera. La primera, queincluyelas parroquias deC annelo y U rbina, con ocho pasosilegales, por los cuales los guerrilleros pasan los sábados, vestidos de civil, para abastecerse en el mercado ecuatoriano. La segunda zona abarcaTulcán y la parroquiaT ufifío y tieneseis pasos. La tercera zona comprendeel sector noroccidental, dondehay ocho caminosno permitidos, todos peatonales ${ }^{26}$.

El presidenteG utiérrez advirtió quea pesar delas dificultades de orden público que mantienen militarizado el territorio norte, existela intención desu país de eliminar las trabasque afectan las relaciones comerciales con Colombia, incluido el cierrenocturno de la frontera queempezó a regir meses atrás. D urantesu entrevista con U ribeen Bogotá, Gutiérrez dijo que "vamosa seguir analizando el tema y lepodría anticipar que levantaríamosesa restricción". Asimismo, manifestó queexigir visado alos colombianostampoco seríauna solución definitiva para evitar la entrada de delincuentes a su país, "porquehay una seriedepasos clandestinosen lasfronteras y porquelosnarcotraficantesy guerrilleros podrían pagar por obtener un visado"27. En total hay 23 pasosilegalesentreColombiay Ecuador a lo largo de la frontera, que permiten a los guerrilleros pasar a este país para abastecerseen el mercado ecuatoriano ${ }^{28}$.

\footnotetext{
${ }^{24}$ Entrevista realizada el de abril deI 2003, en Quito, Ecuador.

${ }^{25}$ Ibid

${ }^{26}$ El Comercio, junio 18 de 2003.

27 "Lucio Gutiérrez no admitirá embajadores de las FARC en Ecuador" http://www.co.starmedia.com/Articulo/ 262148.shtml. Bogotá diciembre 2.

${ }^{28}$ El Comercio, Quito, Ecuador, 18 de junio de 2003.
} 


\section{2) Incremento militar en la frontera}

En su reunión con el mandatario norte americano de comienzos de febrero del 2003, el presidente Lucio G utiérrez aceptó el entrenamiento de los militares ecuatorianos por parte de expertos de los Estados U nidos, con el objeto defrenar la actividad de la guerrilla colombiana en la frontera. En virtud de dichos compromisos, el gobierno anunció un refuerzo de la vigilancia fronteriza, mediantela instalación de dos destacamentos, uno dela M arinay otro del Ejército, además de 1.600 efectivos en la provincia deEsmeraldas. Aunqueno seconoce de manera oficial el número demilitares ecuatorianos que custodian lafrontera con Colombia, seestimaque hay más de 10.000 a lo largo delos más de 6.000 kilómetros $^{29}$. El mandatario ecuatoriano informó quellegarían 18 helicópteros, 100 jeeps y 50 camiones de ayuda militar de los Estados. U nidos ${ }^{30}$. Lo cierto es que los gastos de defensa de Ecuador se incrementaron de 490 millones de dólares en el 2002 a 690 millones en el 2003 y ello tienequever de manera decisiva con lafronteranorte ${ }^{31}$.

D eotra parte, el Comando Conjunto de las Fuerzas Armadas anunció que lastres ramas delas fuerzas militares iniciaron operativos deinterdicción marítima desdela base Eloy Alfaro, de M anta, en M anabí. La fase previa a la ejecución de dichosoperativosse inició con la movilización desde G uayaquil hacia la base de dos aviones radares, tres avionesT -34 y tres helicópteros de la Armada. M anta fue escogida por su ubicación central estratégicay su infraestructura, quepermiten un rápido desplieguehacia el sector nororiental del país ${ }^{32}$.

La utilización de esta base militar para actividades antinarcóticos por parte de los Estados U nidos, en virtud de un convenio suscrito el 12 denoviembredel 999 por el gobierno deJ amil M ahuad, ha generado el rechazo de diversossectores sociales y políticosdel país vecino. D eacuerdo con D iego D elgado Jara, setrata deun acuerdo inconstitucional, porquenunca fueaprobado por el Congreso. El acuerdo establecequeEcuador renuncia a cualquier reclamo "por concepto de daño, pérdida o destrucción de bienes gubernamentales, a consecuencia deactividades relacionadas con esteacuerdo, 0 por concepto delesioneso muertes sufridas por el personal". Pero medianteel artículo 14

\footnotetext{
29 "Presidente confirma que Estados Unidos cooperará a vigilar frontera con Colombia ( sic) " , La Verdad, Ibarra, Ecuador, febrero 14 de 2003, p.3.

${ }^{30}$ El Universo, abril 25 de 2003, p.9A

${ }^{31}$ El Comercio, febrero 14 de 2003, p.6A

${ }^{32}$ www.eluniverso.asp, febrero 27 de 2003.
} 
selehace una concesión adicional a las tropas extranjeras: alasnaves queestén exclusivamenteal servicio no comercial delos Estados U nidosy queestepaís posea u opere, seles otorgará en las base naval es ecuatorianas el mismo trato que a las bases de la Armada $\mathrm{N}$ acional del Ecuador ${ }^{33}$.

En este contexto, el establecimiento dela basemilitar deEstadosU nidosen M anta podría representar un riesgo para la seguridad delosEstadosy una evidente pérdida de soberanía. Algunos medios de comunicación independientesya han al ertado sobrelas implicacionesquepodríatener la instalación deestabasemilitar; seafirma, por ejemplo, que $M$ anta se ha transformado en una estrategia de Estados U nidos para intervenir militarmenteen Colombia, involucrando al vecino paísen la violación cotidiana delos derechosdesoberaníay autodeterminación del pueblo colombiano, lo queabreel riesgo dela extensión del conflicto quedesangraa Colombia ${ }^{34}$.

Frente a la problemática que entrafia la estrategia militar que se está imponiendo sobre la región andina por medio de esteproyecto, AlexisPoncellama la atención sobre el nuevo papel quese le asigna a las fuerzas armadas de la región andino-amazónica y sostiene que en el acápite "Ayuda de Seguridad" se reasignan "nuevos roles" a estos ejércitos, basán doseexclusivamente en losinteresesnacionales de losEstadosU nidos: ya no en el resguardo dela soberanía, sino en el combate a las drogas y a lo queel D epartamento deEstado catal oga como "amenazas real esy actual esa la seguridad nacional" ${ }^{35}$. Tal incremento delosniveles de militarización en la región constituye un factor detensión entre los países de la región, el cual podría desestabilizar sus relaciones económicas, socialesy políticas.

Sin embargo, y acogiendo la nueva prioridad estratégica de enfrentar el terrorismo, el gobierno de G utiérrez aceptó reformular el convenio, de manera quela base se pueda utilizar para el desarrollo de actividades relacionadas con este objetivo. Se sabeque144 vuelos mensuales de los Estados $U$ nidos salen de la base de $M$ anta y se habla de que Gutiérrez estaría negociando la entrega delal sla Baltra, en el archipiélago delas G alápagos, para el establecimiento de otra base militar al servicio del ejército del país del norte ${ }^{36}$. Entre las denuncias que se han hecho en torno a las actividades norteamericanas en la

\footnotetext{
${ }^{33}$ Diego C. Delgado Jara, "Lo que piensa y hace Lucio Gutiérrez", Ecuador. Intermedia, junio de 2003.

${ }^{34}$ http://www.ecuadorindymedia.org/es/2002/08/31.sht1ml.

${ }^{35}$ Ponce, Alexis., Vocero APDHy del grupo civil de monitoreo de los impactos del Plan Colombia en el Ecuador. "Iniciativa Regional Andina: una estrategia integral para tiempos de guerra global" http:// www.derechos.org/ nizkor/colombia/doc/lllan/ecuglob.html, 19 de marzo de 2002. Pág. 2 de II.

${ }^{36}$ El Comercio, marzo 26 de 2003; La Hora, mayo 27 de 2003.
} 
basedeM anta, semenciona quela multinacional estadounidense $D$ ynC orp, quemaneja la logística del Puesto de Avanzada de los Estados U nidos (FO L) en la base, parece dedicarse a actividades antisubversivasal servicio del gobierno desu país, mediantela contratación demercenarios. ${ }^{37}$

En abril de2002, el Subsecretario de Estado norteamericano afirmó quelos grupos terroristaAI Q aeday $\mathrm{H}$ izbula operaban en lazona fronteriza deEcuador con Colombia y Perú, destacando queEcuador necesitaba la ayuda estadounidense para afrontar dicha amenaza. La noticia fue percibida por analistas de ese país como una estrategia tendiente a crear lascondiciones para modificar el convenio deM antay paralograr la asignación de fondos del Plan Colombia, cuando era discutido en el Congreso de los EstadosU nidos. Anteel escándalo provocado por las declaraciones, laEmbajadora deesepaísen Ecuador, K ristieK enney, tuvo que rectificar, señal ando que:

Estamos preocupados por la presencia de seguidores de Ramas y Rizbula en varias regiones de América del Sur, incluyendo el área fronteriza entre Paraguay, B rasil y Argentina, así como la presencia de grupos más pequeños en países como Colombia. Estamos más preocupados aún por los flujos financieros que seguidores y simpatizantes que viven en estas áreas envían a estas agrupaciones en el M edio O riente. ${ }^{38}$

En un informe reciente del Departamento de Estado, su Secretario Colin Powell afirmó que en E cuador "Ios débiles controles financieros del gobierno, la inadecuada preparación del personal de seguridad y el extendido fraude documental limitan los esfuerzos contra el terrorismo"39. Esa declaración permite entender por qué, en lo que respecta a la conflictiva frontera norte de Ecuador, losEstados U nidos han ratificado su intención de continuar apoyando al país vecino con la ejecución deplantes decontención y la ayuda con infraestructura parael control dela violencia en lazona. LaEmbajadora de Washington en $\mathbf{Q}$ uito ha insistido en la necesidad de trabajar juntos en la protección delafrontera. En mayo de2003 inauguró laJ efaturaProvincial Antinarcóticos deSucumbíos, un cuartel construido con losmismos lineamientos castrenses delos de Estados U nidos: cinco bunkers de seguridad, una torre de vigilancia estratégica y una caseta de control vehicular. En su construcción el gobierno norteamericano invirtió dos

37 "DynCorp bajo observación y las Farc no están en Ecuador", La Hora, mayo 4 de 2002.

38 "Estados Unidos aclaró que AI Qaeda no opera en Ecuador", El Comercio, Quito, abril 20 de 2002.

${ }^{39}$ Departamento de Estado, "Pautas deI terrorismo mundial 2002" , citado por Marcelo Larrea, www.llacta.org/ notic/,junio 10 de 2003. 
millones de dólares. La Embajadora anunció igualmente que se construirían cuatro centros decontrol antidrogas en la frontera: en San Lorenzo y M atajeen la provincia de Esmeraldas, Lumbaqui en Sucumbíos y Buenos Aires en el límite entre I mbabura y Esmeraldas, en un lapso de dosaños.

Lo cierto es que las provincias fronterizas con Colombia están experimentando un proceso de militarización sin precedentes. En abril del 2003 el presidente Gutiérrez suscribió el D ecreto Ejecutivo deÁreas deR eserva, queestablecequelaszonas fronterizas se incluirán en el Plan de Guerra de las Fuerzas Armadas. Algunas de las medidas tendientesal establecimiento de estazona deguerra son: la eliminación del libretránsito, la realización deun censo para obtener información sobre las actividades delas personas que viven en el área y el control motorizado, con el apoyo de los suministros de los Estados U nidos. "C olombia lucha por su propia democraciay Ecuador debeayudarla", afirmó la Embajadora en cuestión ${ }^{40}$. Tal como lo señala M arcelo Larrea, con ello se apuntaa lasupresión dederechos civiles constitucionalesinalienables ${ }^{41}$.

\section{3) La frontera norte de Ecuador: crisis social y humanitaria}

En el Segundo Encuentro Internacional de Solidaridad y por la Paz en Colombiay América Latinasemanifestó que, por su naturaleza de contrainsurgencia, el Plan Colombia y su complemento, la I niciativa R egional Andina, se dirigen primordial mentecontrala población civil deColombia y tienen como objetivo inmediato destruir o neutralizar la resistencia de todo sujeto social opuesto al proyecto de reestructuración neoliberal dela economía colombianay latinoamericana. Ademássepuso derelieveel hecho dequetales estrategias producen el desplazamiento masivo hacia países vecinos, dela población civil que ocupa áreas agredidas ${ }^{42}$. Adicional mente, la discriminación dela mujer, la violencia intrafamiliar y el maltrato infantil hacen parte delasmúltiplesviolacionesalos derechos humanosqueocurren en medio delaguerray cuyosefectosinciden en el debilitamiento de la unidad familiar, la estabilidad deloshogares y del tejido social y cultural.

Por otra parte, se observa la problemática derivada del tema medioambiental y dela fumigación de cultivosilícitos. En estesentido, son muchas lascríticasquehan manifestado las organizaciones de derechos humanos, la población civil, al gunos académicosy losmedios de comunicación en general. M aría M onteal egre ${ }^{43}$ sostiene quea pesar dela

\footnotetext{
${ }^{40}$ El Universo, mayo 15 de 2003; Expreso de Guayaquil, mayo 26 de 2003, p.11A

${ }^{41}$ Marcelo Larrea, www. Ilacta.org/notic/,junio 10 de 2003.

${ }^{42}$ Segundo Encuentro Internacional de Solidaridad y por la Paz en Colombia y América Latina. http:/ / www.geocities.com/eventopazl convocatoria2.html.

${ }^{43}$ Maria Montealegre es politóloga de Madrid y reside desde 1996 en Colombia.
} 
defensa de las fumigaciones por parte de los gobiernos colombiano y estadounidense, recientes estudios arrojan queéstas han tenido resultadosn efastos sobrela lucha antinarcóticos; así lo sustenta en una entrevista hecha a G uillermo Taborda, líder campesino de Puerto Asís, quien afirma que "I a falta dealternativas reales de sustitución decultivos hace que los campesinos se desplacen, y desplacen con ellos los cultivos ilícitos para mantener sus rentas". La experiencia delos pactos deerradicación voluntaria, firmados en Puerto Asís en diciembre de2000 entreel gobierno y las comunidades para evitar la fumigación ha sido un fracaso; la ayuda gubernamental de dos millones de pesos en concepto deseguridad alimenticia prometida a los campesinos no hallegado ${ }^{44}$.

A pesar deque estatesis aún no hasido verificada, hay quienesafirman queel uso de las más modernas tecnologías de guerra, incluyendo el dearmas biológicas contra las plantaciones de coca, constituyeun impredecibley grave peligro para la ecología dela zona de biodiversidad más importantedel mundo: la Amazonía ${ }^{45}$. Así semanifiesta el riesgo ambiental que las fumigaciones podrían estar causando en la importantezona ecológica que comparten los países dela región andina.

Sin embargo, algunas organizaciones sociales han asegurado quelasfumigaciones afectan la salud de los habitantes y el medio ambiente, acaban con economías lícitas, promueven desplazamientosy socavan derechosfundamentales, económicos, socialesy ambientales ${ }^{46}$. Asimismo, al gunosmedios de comunicación ya han informado sobreel descontento de las poblaciones que habitan en zonas que son fumigadas; según un informedel diario El U niverso deEcuador, en laH ormiga, Putumayo, los campesinos de la zona fronteriza denunciaron quelas fumigacionesindiscriminadas contralas plantaciones de coca están matando a los animales domésticosy afectan a la población ${ }^{47}$. En Sucumbios, por ejemplo, se denunció que lasfumigacionesa los cultivos de coca en el departamento del Putumayo, están causando pérdidas millonarias alas fincas ecuatorianas asentadasjunto al río San $\mathrm{M}_{\text {igue }}{ }^{48}$.

\footnotetext{
${ }^{44}$ Montealegre, María., "Nada nuevo ", http://www.babab.com/noI2/andes.htm

${ }^{45}$ Segundo Encuentro Internacional de Solidaridad y por la Paz en Colombia y América Latina. http:// www.geocities.com/eventopaz/ convocatoria2 .html.

${ }^{46}$ Declaración de Puerto Asís (Putumayo) del Foro "El Sur Responde al Plan Colombia “. Equipo Nizkor,

${ }^{47}$ Diario EI Universo, "campesinos colombianos denuncian que son fumigados como cucarachas", Ecuador, octubre 4 de 2002. $\mathrm{h}: / /$ www.eluniverso.com/core/eluniverso.asp?page=noticia

${ }^{48}$ Diario El Universo, "Ecuador: Fumigaciones causan daño en Sucumbios". Guayaquil, Ecuador, mayo 15 de 2001. File:// A: *Ecuadorfumigacionescausandañoensucumbios.htm
} 
Bajo estas presunciones, al gunosacadémicosy políticossepronunciaron en el Segundo Encuentro Internacional deSolidaridad y por la Paz en Colombia y América Latina, considerando queel Plan Colombia y la Iniciativa Regional Andina en realidad constituyen un plan militar queinvolucra a los países dela región, los compromete de diversasmaneras en laintervención y se dirige, sin ninguna duda, al control dela cuenca amazónica, afectando la soberanía de los países que la integran ${ }^{49}$. Al respecto, en una entrevista real izada por Julio C ésar Postigo al economistaH ugo C abieses sehabló de que el riesgo dequeesta región, con inmensos recursos naturales, caiga en manos desectores queno puedan ser controlados por los EstadosU nidosponeen peligro, en la concepción de estepaís, su seguridad económica futura, pues hay en la región amazónica importantes recursos petroleros, mineros y madereros, agua potable y materias primas para los descubrimientos delaindustriafarmacéutica ${ }^{50}$.

Es así como las estrategias propuestas por la Iniciativa Regional Andina parecen destinadas a fracasar al igual queel Plan C olombia, por cuanto ya se ha observado que estetipo de medidas no resuelven el problema del tráfico ilícito de drogas y al mismo tiempo podrían provocar la ampliación dela problemática colombiana al resto delos países vecinos. Para Alexis Ponce, referirse al Plan C olombia en los países andinos es hablar de una estrategia desprestigiada y, por lo menos hasta hoy, fracasada: "N i los cultivosilícitos han disminuido, ni las FARC han sido estratégicamentegolpeadas, de ahí quepor parte desus artífices senecesitara consolidar y acelerar una "nueva estrategia", másglobal y - por ello - más riesgosa, por su imposición vertical einconsulta a nuestras sociedades, pero articulada a tradicional es visiones geopolíticas de los Estados U nidos para nuestra región y el continente $e^{51}$. Por otra parte, los resultadosarrojados hasta ahora por el Plan Colombia sugieren que la Iniciativa Regional Andina no representa una solución, a pesar del tratamiento integral del problema delos cultivosilícitos. Esto se debea quelas regiones afectadas son también regionessocial y económicamentemarginales, debido a la ausencia del Estado, la crisis del sector rural, y en general, por los efectos negativos delas reformas neoliberales. M ientrasestas causas estructuralesqueagudizan la

\footnotetext{
${ }^{49}$ Segundo Encuentro Internacional de Solidaridad y por la Paz en Colombia y América Latina. http:/ / www.geocities.com/eventopazl convocatoria2.html.

${ }^{50}$ Cabieses, Hugo. Consultor asociado del Instituto Interamericano de Cooperación para la Agricultura IICA en desarrollo rural y políticas de drogas. Plan Colombia o Plan Estados Unidos, http://www.cepes.org.pe/revista/ragra30/arti-0Ia.htm.

${ }^{51}$ Ponce, Alexis., Vocero APDHy de] grupo civil de monitoreo de los impactos del Plan Colombia en el Ecuador. "Iniciativa Regional Andina: una estrategia integral para tiempos de guerra global.' http://www.derechos.org/ nizkor/colombia/doc/plan/ecuglob.html, 19 de marzo de 2002. Pág. 2 de 11.
} 
violencia y la pobreza no estén contempladas para la resolución del problema del narcotráfico, cualquier estrategia militar implementadafracasará por intentar resolver tal problemáticaatacando infructuosamentelas consecuencias quese derivan dela compleja realidad de subdesarrollo y dependencia que se viveen la región.

\section{Conclusión}

El desplazamiento forzado de colombianoshacialos países andinosesel resultado de la exacerbación delosfactores deviolencia y del deterioro delas relacioneseconómicasy sociales en el país, como consecuencia de la puesta en práctica de las tres estrategias prioritarias derivadas del N uevo O rden M undial: la lucha contra el narcotráfico, las políticas de liberalización económica y comercial y, más recientemente, la cruzada antiterrorista. ParaC olombiay la región, estas estrategias se concretan en el Plan C olombia y en la Iniciativa Regional Andina.

Las ópticas a partir de las cuales se aborda la estrategia que propone la I niciativa Regional Andinaseencuentran ampliamentepolarizadas. Laversión oficial sostieneque esta estrategia solucionará el problema de las drogasilícitas y la crisis social en el sur del paíspor atacarlos demanera integral, es decir, creando un muro decontención en las fronteras colombianas con los países vecinos para evitar la propagación y desplazamiento deloscultivosilícitos hacia otros países de la región. Pero desdela óptica de quienes se oponen a ella, Ia Iniciativa R egional Andina es un proyecto intervencionistay militar, destinado a agravar la crisis económica y social quehoy en día seviveen las zonas desu aplicación.

En el presente trabajo se demuestra que la aplicación del Plan Colombia y de la Iniciativa Regional Andina ha tenido una incidencia negativa muy claraen la situación delospaíses dela región, en especial Ecuador. Políticas derivadas deestosdosplanes, tales como la fumigación intensiva de cultivos ilícitos con productosquímicoscuya utilización ha sido cuestionada nacional einternacional mente, y el incremento militar en la frontera, han contribuido a exacerbar el problema del desplazamiento forzado transfronterizo hacia el país del sur. Losinformes y estudios consultados de los organismosinternacionales, en especial Acnur, o de las entidades nacionalesy locales ecuatorianas oficialesy no oficiales, como la D efensoría del Pueblo, losministeriosde Relaciones Exteriores y del M edio Ambiente, O ipaz, Acción Ecológica, y el Episcopado ecuatoria no, coinciden en esa afirmación. Losresultados del trabajo de campo, como las entrevistas realizadas a los propios actores, también corroboran el impacto negativo del Plan Colombiay lal niciativa Regional Andina.

La prensa y los medios del país vecino también han registrado profusamente esta problemática desde finales del 2000, cuando comenzó la aplicación del Plan Colombia. 
D ela misma manera, han puesto en evidencia que el problema se ha agravado como consecuencia de las políticas de Seguridad D emocrática del gobierno de U ribe V élez durante el último año. En un contexto deviolencia general izada, cuyos rasgossobresalienteshan sido un incremento delas disputasterritorialesentreparamilitares y guerrilleros, la amenaza contra las autoridades locales, el acentuamiento delas políticas represivas del Estado y de las fumigaciones aéreas, el problema del desplazamiento forzado de colombianos hacia Ecuador ha aumentado demanera notoria.

Como consecuencia de esta situación, las relaciones bilaterales entre Colombia y Ecuador sehan visto afectadas. D istintos sectores sociales y políticos del país vecino han venido presionando paraqueel Estado colombiano adopteunas medidas claras frenteal problema del incremento de la violencia y del desplazamiento forzado. En diversas reuniones bilaterales quese han realizado entrelosmandatarioso entrefuncionariosde ambospaíses, el gobierno ecuatoriano ha insistido también en dos puntos: primero, que su contraparteadoptelasmedidas necesarias, tales como respetar la franja de diez kilómetros del lado colombiano dela frontera, como límitepara que la fumigación no afecteal territorio ecuatoriano; y segundo, que se emprendan medidas claras para afrontar el problema de los desplazados colombianos.

\section{Referencias}

AC OSTA, A. “Intervención en el foro: 'EI Plan Colombia: visiones críticas desde el Congreso, la academia y las regiones' ",I n: Revista N ueva Gaceta nํ 3, abril 18 de 2001. Bogotá: Universidad Javeriana.

AH U M ADA, C.\& M OREN O A. “El desplazamiento forzado de colombianoshaciala región andina y su impacto sobre la situación política regional", In: Comunidad Andina y M ercosur en la perspectiva del ALCA, Centro Editorial Javeriano, 2003.

AN D EAN “Regional I nitiative(AR!): FY2002 Supplemental and FY2003" Assistance for Colombia and $N$ eighbors, enero 8 de 2003.

ARD ILA, M \& \& CARD O N A, D . et al. Prioridadesy desafíosdela política exterior colombiana, Fescol, Introducción, 2002.

ARDILA M . "La política exterior de Colombia hacia sus vecinos. Evolución, mecanis mosy retos", In: M artba Ardila, D iego Cardona y O tros, op.cit, 2002.

BO RD A, S. "La política exterior colombiana antidrogaso cómo sereproduceel ritual realista desdeel tercer mundo", In: ARD ILA, M artha, CARD O N A, D iego et al, Prioridadesy D esafíos dela Política Exterior Colombiana, Fescol, 2002.

BUSTILLO , J. M ."La O rganización dela Población D esplazaday la Reconstrucción del Tejido Social", In: D esplazamiento Forzado Interno en Colombia: Conflicto, Paz y Desarrollo, ACN U R-C O DEES, 2001. 
CAYCED O , G. C. Sin Tregua. Bogotá: Editorial Planeta, 2003.

CISP. "La frontera del desplazamiento", Análisis de la Situación del D esplazamiento hacia Ecuador dela Población A fectada por la Violencia en Colombia, 2000. In: Situación yD escripción delas Características deD esplazamiento.

CODH ES. Caracterización Socioconómicay Política delasZonasdeFrontera deColombia, 2002.

DEFEN SO RÍA “D elegada paral ndígenasy M inoríasÉtnicas”, In: Informe, julio de2001.

FAJARD O , D. "Para Sembrar Paz hay queAflojar laTierra”, In: Institu to deEstudios Ambientales, IDEA, U niversidad N acional deC olombia, 2001.

"El Plan Colombiay laInternacionalización delaGuerra”, In: ALVAREZ, J. E. (ed.), El Plan Colombia yla Intensificación dela Guerra, U niversidad N acional deColombia, 2002.

GRU N ER, S. "D esplazamiento Forzoso, Políticas Externasy Comunidad Internacional", In: D estierro y D esarraigos, M emorias del II Seminario Internacional, D esplazamiento: I mplicacionesy retospara la gobernabilidad, la democracia y losderechos humanos, Bogotá, C olombia: CO D H ES, O IM , 2002.

GUTIÉRREZ, O. Estructura dela Propiedad Rural y Sistema deTenencia deTierra en Santander. Bucaramanga: Funprocep, ALO P, 1990.

IN TERN ATIO N AL C risisG roup. Colombia ysusVecinos losTentáculosdela Inestabilidad, 2003.

M ACH AD O , A. La Cuestión A graria en Colombia a Finesdel M ilenio, El Áncora Editores, 1998.

M ACK, J. International Information Programs, Washington file, Text: StateD ept.O fficial Reviews G oals of U .S. Policy in Andes, junio 28 de 2001.

M O LAN O , A. LosAñosdel Trope: CrónicasdelaViolencia, Bogotá: El ÁncoraEditores, 1985. . Entrela Coca y el O ro. Bogotá: El Áncora E ditores, 1990. D esterrados. Crónicas del D esarrai go, Bogotá: El Áncora Editores, 2001.

N ARAN JO, G. \& DEICY H . 2002. “El derecho ala liudad. M igrantesy desplazadosen las ciudades colombianas", artículo derivado del proyecto de investigación: D esplazamiento forzado y reconfiguracionesurbanas El caso deM edelín y de área metropolitana 1992-2002, Instituto deEstudios Políticos, Universidad deAntioquia.

N O RD GREN , R. “ ¿Responderealmentela cooperación internacional alo queC olombia necesita?", In: D esplazamiento Forzado Interno en Colombia: Conflicto, Paz yD esarrollo. M emoriasSeminario I nternacional, ACN UR-C O D H ES, 2000.

O ACN UDH , ACN U R, CO D H ES. Compilación sobreD esplazamiento Forzado. N ormasD octrinasyJurisprudencia $\mathrm{N}$ acional el nternacional, Bogotá, 2001. 
OIPAZ. Testimonios de Frontera. Efectos del Plan Colombia en la Frontera ColomboEcuatoriana. Q uito, 2002.

PO N CE, A. "Vocero del Grupo Civil deM onitoreo delosI mpactosdel Plan Colombia en el Ecuador", In: Iniciativa Regional Andina: una Estrategia Integral para Tiempos de Guerra Global, http://www.derechos.org/nizkor/colombia/doc/olan/ecuglob.html, 2002.

PRESIDEN CIA delaRepública. LosD esplazados, esa Colombia queno Podemosi gnorar, Bogotá: abril, 1998.

RAM ÍREZ, S. "La internacionalización del conflicto y dela paz en Colombia”, En: ALVARO , J. E.(ed), Plan Colombia, EnsayosCríticos, op.cit, 2001.

RO M ERO, M. “La Política en la Paz y la Violencia”, AnálisisPolítico N 0.45, IEPRI, abril,2002.

SÁN CH EZ, R. El N eointervencionismo yla Pax Americana, ibid, 2001.

STALLIN GS, B. "La Influencia Internacional en las Políticas Económicas: D euda, Estabilización y R eforma Estructural", In: H AG GARD, Stephan y KAUFM AN, Robert R. (compiladores). La Política de Ajuste Económico. Las Restricciones Internacionales, los ConflictosD istributivosy el Estado, Bogota: Cerec, 1992.

TH O U M I, F. El I mperio dela D roga. N arcotráfico, Economía y Sociedad en losAndes, IEPRI-Planeta, 2002

TICKN ER, A. B.. "LaG uerracontralasD rogas: lasR elacionesC olombia-EstadosU nidosdurantelaAdministración Pastrana", In: ALVAREZ, J. E. (editor), Plan Colombia. op.cit, 2001.

TICKNER, A. B. '“C olombia” eslo quelosActoresEstataleshacen deElla: una(Re)lectura delaPolíticaExterior ColombianahacialosEstadosU nidos", In: ARDILA, M artha, op.cit, 2002.

TO RO , C. "N arcotráfico: lo quela Interdependencia no nosExplicó", La Política Exterior deM éxico: Enfoquespara su Análisis, M éxico: EI Colegio deM éxico, Instituto M atías Romero de EstudiosD iplomáticos, 1997.

M ESA, R. V., (compilador). D rogas, Poder y Región en Colombia, Impactos L ocales y Conflictos, Bogotá: CIN EP, volumen 2, 1994.

“D rogas, Seguridad y D emocracia en América Latina”, In: ALVAREZ, J. E. (compilador), EI Plan Colombia y la Intensificación dela Guerra, U niversidad $\mathrm{N}$ acional deC olombia, 2002.

VASCO , L.G. "D esplazamiento Forzado y Reconstitución Cultural” In: Éxodo, Patrimonio el dentidad, 5a C átedra dehistoriaErnesto Restrepo T irado, M useo N acional, 2000.

ZULUAGA, J. "GuerraProlongada, N egociación Incierta: Colombia”, In: LEÓ N , R. B. (compilador), Violencia, Sociedad y Justicia en América Latina, Buenos Aires: FLACSO , 2002. 